\title{
How to carry out market research in large-data-era enterprise
}

\author{
Mei Huang \\ Jiangxi Vocational Technical College Of Industry \& Trade, Jiangxi, Nanchang,330038
}

\author{
key words Big Data Age; Enterprise; Market Research
}

\begin{abstract}
In the traditional market research data, the enterprise is the main user, but in the large data age, whether the data is collected, or the way of processing the data, there has been a great change, and the market research in the big data era is different from that in the past, However, the appearance of the big data era does not hinder the development of the enterprise, but it has promoted the market research activities of the enterprise, and the paper analyzes and discusses the market research of the enterprise mainly under the background of big data.
\end{abstract}

\section{The past market research activities of the enterprise}

the large data can collect and analyze the information, and the information such as the behavior habit and the consumption preference of people on the network can be collected by the big data, At the same time, because people are more or less exposed to their phone numbers or other privacy information online, people are always able to receive a sales call, and the salesman can tell the consumer's consumer preference and the demand for the product. Some people think that this existence has an effect on their private life, and some people think that makes their own life Life is more convenient, but, in any case, it is indisputable that big data has a very important role for enterprise market research, and the use of big data for market research is not only fast, but also efficient.

\subsection{The market research activities in our country are in a late stage}

The enterprise is not aware of the importance of market research in recent years, but it has been realized in the past that the importance of market research has been realized, but the development of market research is very complicated and the energy and manpower are consumed, so the effect of market research is not very ideal. Only a very small number of enterprises use market research to make the correct operation decision, and get more economic benefits, but this is not just because the big data has not yet been generated, also because the market research activities of our country started later, There is no further analysis and research on market research.

\subsection{The main features and limitations of market research activities in our country}

In order to carry out enterprise market research, first of all, it is necessary to make clear the purpose of research, have a clear orientation of research purpose, the data obtained after investigation is more accurate and applicable, at the same time, market research should be based on the actual market situation, and the data should be more objective and comprehensive, effective market research can help enterprises to make business decisions, and ineffective market research is only a waste of enterprise energy and time. Therefore, enterprises should do a good job of research plans before carrying out market research.

\section{The Necessity of Market Research in Enterprises}

There is no doubt about the importance of market research in enterprises, and enterprises will also make scientific decisions through effective market research data. For the development of enterprises, the necessity of market research mainly lies in the following aspects:

\begin{tabular}{|c|c|}
\hline \multicolumn{2}{|c|}{ The Necessity of Market Research for Enterprise's Economic Development } \\
\hline Understand the market demand & Set up the image of the enterprise \\
\hline Identify opportunities for marketing & boosting the competitiveness \\
\hline
\end{tabular}




\subsection{Understand the market demand and find the marketing opportunity}

if the product can be sold well in the market, the enterprise must promote the product more and innovate the product, and the demand of the market and the consumer is also very important, according to the demand of the market and the consumer's demand, the innovation of the product is the most effective sustainable development road, and the main market research needs to know the consumer orientation of the consumer and the consumer's consumer habit and the consumer's expectation of the product, so the enterprise can update and transform the product according to the research result, and meanwhile, The enterprise should spare no effort to promote the product and develop the marketing plan. Of course, market research The effect of the product is not only reflected in the innovation plan of the product, but also in the development plan of the product, And the economic benefit of the enterprise is improved. The enterprise can only hold the market trend and the consumer's propensity to consume, can make a place in any market environment.

\subsection{Set up the enterprise image and improve the competitive ability}

For enterprises, it is very important to create a good image, the image of the enterprise is equivalent to the brand of the enterprise, can leave a deep impression on consumers, but also can promote the development of the market, and using market research, enterprises can cater to the needs of consumers from all aspects, establish a good corporate image in the hearts of consumers, and enterprises want to form a long-term transaction relationship with consumers. It is necessary to establish a good corporate image in the hearts of consumers, so that consumers are satisfied with the enterprise, but also let consumers loyal to the enterprise, so that when the enterprise launches new products, loyal to the consumer of the enterprise, even if they do not understand the production of the enterprise. The products will also be consumed and tried, and when there are similar products and enterprise products to compete, the loyal consumers will also choose the products of the enterprise, which is the impact of the enterprise image. At the same time, the enterprise cannot ignore the importance of the consolidation of the customer, the customer relationship is the need to be maintained, only to give the loyal customer more benefits and rewards, the customer can contact with the enterprise for a long time, and make oral propaganda for the enterprise. To consolidate the relationship between the enterprise and the customer, it is also necessary for the enterprise to have a certain understanding of the customer, which can be obtained through market research, which is the core competition factor in the market competition and who. If you have more information, whoever can compete in the market will be slightly better. Therefore, enterprises need to pay more attention to market research, through big data to obtain more market information.

\section{The Market Research Activities of the Enterprise in the Big Data Era}

The definition of big data and market research is completely different, but there is no contradiction between big data and market research, and it is even mutually reinforcing. In the big data era, enterprises can do market research without consuming so much energy and ability, so long as big data is used, The enterprise can easily get more market information and consumer information.

\subsection{The collection of large data is dependent on information technology, in particular the use of the Internet}

while the wide range of applications of large data is not so perfect in some areas, the consumption habits and consumption preferences of the consumer groups of many products cannot be transferred through the internet, and in this case, The traditional market research method is still very necessary, so that the collected market data has a certain role to the enterprise.

\section{2 there are still barriers to the use of big data for many enterprises}

As far as the present stage is concerned, whether in the field of computer or in the field of ecommerce, big data's application is very extensive, but some enterprises do not have a strong consciousness of applying big data, especially small and medium-sized enterprises. Big data can help enterprises to carry out diversified market research activities and help enterprises to enhance 
certain economic benefits, and because of its own characteristics, big data can help enterprises to carry out diversified market research activities and help enterprises to enhance certain economic benefits. It is difficult to collect data from a smaller area, so it is very important for both traditional market research activities and market research activities under the background of big data. Enterprises still need to make use of these two kinds of research activities at the same time to make use of these two kinds of research activities for enterprises. To promote the development of.

\section{Conclusion:}

At present, the market competition is fierce, while enterprises seize many opportunities, but also face a lot of challenges, and through big data market research, enterprises can better understand the changes in the market and consumers' consumption tendency, but also can grasp the supply and demand of products, understand the needs and expectations of consumers, and carry out product development and innovation to maximize the interests of enterprises. Therefore, enterprises must realize the importance of market research, whether through big data market research, or traditional market research methods, can bring more or less help to enterprises, so enterprises should also vigorously develop market research.

\section{References:}

[1] A brief talk on big data's informatization and database construction [J]. Xie Shuqin. China's new communications. 2016 (22)

[2] Data-intensive science and health information behavior from the perspective of big data [J]. Song Meijie. Modern Communication (Journal of Communication University Of China). 2016 (11)

[3] since the 21st century, the hot field and frontier theme of community education research in China-based on the knowledge graph analysis of the literature published in CNKI database [J]. Wang Yonggang, Yin Yuxin. Vocational education forum. 2016 (33)

[4] investigation report on the present situation of ergonomics design in Nanjing furniture market [J]. Zhu Yongheng. Design。 2016 (06)

[5] Investigation and analysis of Guangzhou furniture campus [J]. Zheng is the time. Modern decoration (theory) 2016 (02)

[6] the role of market research in initial entrepreneurship: a case study of art trading platform [J]. Han Xi, Qi Mingming. Modern economic information. 2016 (07) 